\title{
What Most Influence Quality of Sleep in Parkinson`s Disease Patients?
}

Svetlana Tomic ${ }^{1 *}$, Marina Hlavati², Marta Petek', Mirjana Cubra1', Tomislav Pucic ${ }^{1}$, Tea Mirosevic Zubonja ${ }^{1}$, Stjepan Juric ${ }^{1}$, Anamarija Soldo Koruga', IvankaStenc Bradvica' and Silva Butkovic Soldo ${ }^{1}$

${ }^{1}$ Department of Neurology, University Hospital Centre Osijek, Osijek, Croatia

${ }^{2}$ Department of Neurology, General Hospital Nasice, Nasice, Croatia

\begin{abstract}
Study objective: Sleep disturbances are one of the most common non-motor symptoms of Parkinson's disease that influence on the quality of life. Our aim was to investigate the incidence of sleep disturbances in patients with idiopathic Parkinson Disease and to evaluate what type of sleep disturbance influence most on the quality of the sleep in these patients.
\end{abstract}

Methods: One hundred and four Parkinson Disease patients treated in the University Hospital Centre Osijek and General Hospital Nasice were analysed. The patients were assessed with regards to whether or not they were experiencing sleep disturbances and were divided accordingly into two groups: those that did not have sleep disturbances and those that experienced sleep disturbances. All of the patients completed Parkinson Disease Sleep Scale.

Results: Sleep disturbance was reported in $58 \%$ patients, while $42 \%$ did not report to have sleep disturbance. Sleep disturbances group recorded lower mean result in Parkinson Disease Sleep Scale as well as lower mean results for each sub-scale for all symptoms except incontinence due to immobility compared to group with no sleep disturbances. We found statistically significant difference between two groups of patients on these items: quality of sleep ( $t=-3.046$; $\mathrm{p}<0.005)$, maintenance of sleep $(\mathrm{t}=-2.869 ; \mathrm{p}<0.005)$, distressing dreams $(\mathrm{t}=-2.947 ; \mathrm{p}<0.005)$ and fatigue $(\mathrm{t}=-2.494$ $p<0.01$ ). Regresion logistic analysis predict sleep disturbances significantly (omnibus chi-square $=41,387, d f=17, p<.001$ ) with quality of sleep, distressing dreams and painful posturing as most predictive variable for sleep disturbances in SD group.

Conclusion: Nocturnal awakening, distressing dreams and fatigue influence most on the quality of sleep in patients with Parkinson's disease. Variables that proved to be most significant predictors for sleep disturbance of PDSS are quality of sleep, distressing dreams and painful posturing.

Keywords: Parkinson disease; Sleep disorders; Parkinson disease sleep scale; Quality of sleep; Neurodegenerative disease

\section{Introduction}

In Parkinson `s Disease (PD) patients quality of life depends mostly on sleep disturbances, depression, cognitive impairment and motor disability [1-3]. Among those, sleep disturbances are one of the most common non-motor symptoms of PD with prevalence that varies from $60-98 \%$ of the cases [4]. There are two types of sleep disorder in PD patients: noctural sleep disturbances and excessive daytime sleepiness [4]. Noctural sleep disturbance may be caused by sleep fragmentation, sleep apnea, restless leg syndrome, periodic limb movements, REM sleep behavior disorder, night time hallucinations and nightmares [4].

The objective of this study was to determine frequency and severity of sleep disturbances in PD patients and to find out what sleep disturbance influence most on quality of the sleep.

\section{Patients and Methods}

Patients treated on the Department of Neurology in The University Hospital Center Osijek and on the Department of Neurology in The General Hospital Našice were surveyed for sleep disorders. All the patients met UK Brain Bank criteria for idiopathic Parkinson disease [5]. Data about age, sex and disease duration were obtained. Patients were queried if they have any sleep difficulties and according to this answer patients were divided into two groups: those with no sleep disorders (NSD) and those with sleep disorders (SD). All the patients were asked to fill up Parkinson Disease Sleep Scale (PDSS) [6]. Movement Disorder task force recommended this scale for rating overall sleep problems (to screen and to measure severity) [7]. As the PDSS is employed as part of routine clinical practice and audit in the outpatient clinic assessment of patients with PD, we did not ask institutional ethics committee for specific ethical approval. The PDSS is a visual analogue scale evaluating
15 commonly reported symptoms associated with sleep disturbance (quality of night's sleep, sleep onset and maintenance insomnia, nocturnal restlessness, nocturnal psychosis, nocturia, nocturnal motor symptoms, fatigue and daytime sleepiness). The actual scale is presented to patients, who are asked to mark their responses according to severity by placing a mark on the $10 \mathrm{~cm}$ line. The $\mathrm{mm}$ scale, which is printed on a transparency, is then applied on the $10 \mathrm{~cm}$ lines to measure the responses in decimal figures; 10 represents excellent/never responses; 0 represents the worst score.The maximum cumulative score for the PDSS is 150 (patient is free of all symptoms) [6]. Major disadvantage of the PDSS scale is it's semiquantitative nature.

Descriptive statistics were performed to calculate the average values and standard deviation for each of the PDDS items. Independent samples t-test were used to perform a pair-wise comparisons between two groups. We perform logistic regression analysis with PDSS subscales, age and sex as a predictor variables and groups of the patients with or without sleep disturbances as criterion variable. The data were analyzed using SPSS 12.0 for Windows. A level of significance of $\mathrm{p}<0,03$ was used.

*Corresponding author: Svetlana Tomic, Department of Neurology, University Hospital Center Osijek, J. Huttlera 4, 31000 Osijek, Croatia, Tel: +385/91/5244485; Fax: +385/31/512-216; E-mail: svetlana.tomic@vip.hr

Received February 13, 2014; Accepted March 23, 2014; Published March 26 2014

Citation: Tomic S, Hlavati M, Petek M, Cubra M, Pucic T, et al. (2014) What Most Influence Quality of Sleep in Parkinson`s Disease Patients? J Neurol Disord 2: 152. doi:10.4172/2329-6895.1000152

Copyright: @ 2014 Tomic S, et al. This is an open-access article distributed under the terms of the Creative Commons Attribution License, which permits unrestricted use, distribution, and reproduction in any medium, provided the original author and source are credited. 


\section{Results}

We had analyzed 104 patients (58 male and 46 female). Sixtyone patients (58\%) reported to have sleep disturbances (SD) while 43 patients (42\%) did not report any (NSD). Mean age of the patients was 71.93 (median 73 years) in SD group and 68.56 (median 70 years) in NSD group. There was no significant differences between this two groups according $(\mathrm{p}<0.06)$. Mean disease duration was 6.07 years (median 6 years) in SD group and 4.91 (median 2 years) in NSD group. There also was no significant differences between two groups $(\mathrm{p}<0.215)$. In SD group there were predomination of the malepatients (24 female and 37 male) while in NSD group there were equal number of the patients regarding to sex (22 female and 21 male). Total PDSS score was higher in NSD group (104.391) compared to SD group (87.664). In the SD group mean result for each sub-scale was lower for all the symptoms except for incontinence due to immobility compared to NSD group (Table 1). Statistically significant differences between this two groups were observed in sub-scales quality of sleep $(t=-3.046 ; \mathrm{p}<0.003)$, maintenance of sleep $(\mathrm{t}=-2.869 ; \mathrm{p}<0.008)$, distressing dreams $(\mathrm{t}=-$ 2.947; $\mathrm{p}<0.004)$ and fatigue $(\mathrm{t}=-2.494 ; \mathrm{p}<0.014)$ (Table 1$)$. Regression logistic analysis predict sleep disturbances significantly (omnibus chisquare $=41.387, \mathrm{df}=17, \mathrm{p}<.001$ ) with quality of sleep, distressing dreams and painful posturing as most predictive variable for sleep disturbances

\begin{tabular}{|c|c|c|c|c|c|}
\hline & SD/NSD & Mean & $\begin{array}{l}\text { Std. } \\
\text { Deviation }\end{array}$ & $\mathbf{t}$ & $\begin{array}{l}\text { Sig. } \\
\text { (2-tailed) }\end{array}$ \\
\hline \multirow[t]{2}{*}{ Quality of sleep } & SD & 5.190 & 2.9177 & -3.046 & \\
\hline & NSD & 6.974 & 2.9760 & -3.035 & .003 \\
\hline \multirow[t]{2}{*}{ Falling asleep } & SD & 6.390 & 3.8298 & -1.420 & \\
\hline & NSD & 7.477 & 3.8632 & -1.418 & .159 \\
\hline \multirow[t]{2}{*}{ Maintenance of sleep } & SD & 2.007 & 2.8501 & -2.869 & \\
\hline & NSD & 3.912 & 3.9253 & -2.717 & .008 \\
\hline \multirow[t]{2}{*}{ Restlessness } & SD & 5.902 & 4.0853 & -1.941 & \\
\hline & NSD & 7.398 & 3.5431 & -1.989 & .055 \\
\hline \multirow[t]{2}{*}{ Fidget } & SD & 4.528 & 3.9959 & -1.256 & \\
\hline & NSD & 5.523 & 3.9584 & -1.258 & .212 \\
\hline \multirow[t]{2}{*}{ Distressing dreams } & SD & 6.685 & 3.6580 & -2.947 & \\
\hline & NSD & 8.563 & 2.3978 & -3.160 & .004 \\
\hline \multirow[t]{2}{*}{ Distressing hallucinations } & SD & 8.120 & 3.2642 & -1.956 & \\
\hline & NSD & 9.188 & 1.7480 & -2.156 & .053 \\
\hline \multirow[t]{2}{*}{ Nocturia } & SD & 2.025 & 3.1831 & -1.826 & \\
\hline & NSD & 3.309 & 3.9808 & -1.757 & .071 \\
\hline \multirow[t]{2}{*}{ Incontinence } & SD & 8.272 & 3.3288 & .183 & \\
\hline & NSD & 8.149 & 3.4811 & .181 & .856 \\
\hline \multirow[t]{2}{*}{ Numbness } & SD & 7.395 & 3.6093 & -.996 & \\
\hline & NSD & 8.088 & 3.3228 & -1.011 & 321 \\
\hline \multirow[t]{2}{*}{ Cramps } & SD & 6.525 & 3.6383 & -.874 & \\
\hline & NSD & 7.144 & 3.4467 & -.882 & .384 \\
\hline \multirow[t]{2}{*}{ Painful posturing } & SD & 7.702 & 3.6438 & .380 & \\
\hline & NSD & 7.426 & 3.6594 & .380 & .705 \\
\hline \multirow[t]{2}{*}{ Tremor } & SD & 6.359 & 4.1302 & -2.135 & \\
\hline & NSD & 7.947 & 3.0836 & -2.243 & .035 \\
\hline \multirow[t]{2}{*}{ Fatigue } & SD & 5.657 & 4.2181 & -2.494 & \\
\hline & NSD & 7.614 & 3.5059 & -2.575 & .014 \\
\hline \multirow{2}{*}{$\begin{array}{l}\text { Unexpectedly falling } \\
\text { asleep during day }\end{array}$} & SD & 4.864 & 4.3831 & -1.256 & \\
\hline & NSD & 5.960 & 4.3886 & -1.255 & .212 \\
\hline \multirow[t]{2}{*}{ Total } & SD & 87.664 & 29.2974 & -2.887 & \\
\hline & NSD & 104.391 & 28.8097 & -2.895 & .005 \\
\hline
\end{tabular}

PDSS-Parkinson Disease Sleep Scale; SD-Sleep Disturbance; NSD-No Sleep Disturbance

Table 1: Results of PDSS in total and for each subscale between group with no sleep disturbance (NSD) and those with sleep disturbance (SD).

\begin{tabular}{|l|l|l|l|l|l|l|}
\hline Variable & B & S.E. & Wald & df & Sig. & Exp(B) \\
\hline Quality of sleep & .291 & .120 & 5.831 & 1 & .016 & 1.337 \\
\hline Falling asleep & .045 & .084 & .294 & 1 & .588 & 1.047 \\
\hline Awakening & .177 & .093 & 3.575 & 1 & .059 & 1.193 \\
\hline Restlessnes & -.016 & .095 & .027 & 1 & .868 & .984 \\
\hline Fidget & -.160 & .094 & 2.921 & 1 & .087 & .852 \\
\hline Distressing dreams & .244 & .121 & 4.043 & 1 & .044 & 1.276 \\
\hline Distressing halucinations & .131 & .142 & .858 & 1 & .354 & 1.140 \\
\hline Nocturia & -.033 & .083 & .157 & 1 & .692 & .968 \\
\hline Incontinetia & -.150 & .095 & 2.514 & 1 & .113 & .861 \\
\hline Numbness & .009 & .117 & .006 & 1 & .937 & 1.009 \\
\hline Cramps & .037 & .111 & .110 & 1 & .740 & 1.038 \\
\hline Painful posturing & -.252 & .111 & 5.126 & 1 & .024 & .778 \\
\hline Tremor & .096 & .084 & 1.304 & 1 & .253 & 1.101 \\
\hline Fatigue & .110 & .086 & 1.616 & 1 & .204 & 1.116 \\
\hline Unexpectedly falling & .015 & .073 & .043 & 1 & .836 & 1.015 \\
\hline asleep during day & & & & & & \\
\hline Age & -.049 & .034 & 2.096 & 1 & .148 & .952 \\
\hline Sex & 1.104 & .602 & 3.360 & 1 & .067 & 3.016 \\
\hline Constant & -.675 & 2.621 & .066 & 1 & .797 & .509 \\
\hline
\end{tabular}

Table 2: Regression logistic analysis with PDSS subscales, age and sex as a predictor variables and group of the patients with sleep disturbances as criterion variable.

in SD group (Table 2). This model explain variance between $32.8 \%$ and $44.2 \%$ in sleep disturbances. In SD group analysis correctly predict in $82 \%$, while in NSD group in $58.1 \%$. Total accuracy of prediction was $72.1 \%$.

\section{Discussion}

More than the half of the patients reported to have sleep disturbances ( $58 \%$ in respect to $42 \%$ ). Mean disease duration between two groups did not differ significantly (4.91 in respect to 6.07 ), but median (2 years in respect to 6) was different pointing that in NSD group most of the patients had early while in SD group moderate to advance PD. There was slight difference in mean age of the patients between this two group (71.93 in respect to 68.56) but this difference was not significant. So, we found no impact of the age on sleep disturbances. Maintenance of sleep, distressing dreams, and fatigue appears to be the symptoms that mostly influence on the quality of the sleep in our patients. Variables that proved to be most significant predictors for sleep disturbance of PDSS are quality of sleep, distressing dreams and painful posturing.

Sleep disorders can also occur in the early stages of PD [8], and some of them,as REM sleep movement disorder and excessive day time sleepiness, can even be powerful and prodromal marker for PD and other synucleinopathies [4,9], but these non-motor symptoms mostly appear in moderate to severe PD $[4,8,9]$. Dhawan et al. find that nocturia, night-time cramps, dystonia, tremor and somnolence seem to be the important nocturnal disabilities in treatment naive Parkinson disease patient probablly due to lack of dopaminergic stimulation [10] while Spanish group of authors find thaturinary incontinence, nighttime restlessness, morning fatigue and somnolence are the variables that mostly affect the quality of life in group of patients with moderate to severe Parkinson disease [11].

Parkinson disease patients are elderly population with other chronic disease seeking for treatment. Advanced stage of PD requires also usage of the large amounts of various drugs. All this could influence on drug compliance. According to our data difficulties in maintenance of sleep, distressing dreams, fatigue and painful posturing should be treated in order to improve quality of sleep in PD patients. Some of these sleep 
Citation: Tomic S, Hlavati M, Petek M, Cubra M, Pucic T, et al. (2014) What Most Influence Quality of Sleep in Parkinson`s Disease Patients? J Neurol Disord 2: 152. doi:10.4172/2329-6895.1000152

disturbances are treatable conditions and they should be recognized by clinicians and managed properly.

\section{Conclusion}

Appropriate diagnosis of the sleep disturbance affecting a PD patient can lead to specific treatments that can consolidate nocturnal sleep and enhance daytime alertness. Improved sleep at night has ripple effect. Often improves mood and day time motor function and decreases motor fluctuations.

\section{Acknowledgements}

Parkinson Disease Sleep Scale in Croatian version was provided by Glaxo Smith Klein Pharmaceutical.

\section{References}

1. Gallagher DA, Lees AJ, Schrag A (2010) What are the most important nonmotor symptoms in patients with Parkinson's disease and are we missing them? Mov Disord 25: 2493-2500.

2. Zhou MZ, Liu ZG, Gan J, Chen W, Lu LX, et al. (2008) [Neuropsychiatric problems in patients with Parkinson's disease]. Zhonghua Yi Xue Za Zhi 88: 1442-1445.

3. Schrag A, Jahanshahi M, Quinn N (2000) What contributes to quality of life in patients with Parkinson's disease? J Neurol Neurosurg Psychiatry 69: 308-312.
4. Comella CL (2007) Sleep disorders in Parkinson's disease: an overview. Mov Disord 22: S367-373.

5. Huges AJ (1992) UK Parkinson's Disease Society Brain Bank Clinical Diagnostic Criteria. Neurol Neurosurg Psychiatry 55: 181-184.

6. Chaudhuri KR, Pal S, DiMarco A, Whately-Smith C, Bridgman K, et al. (2002) The Parkinson's disease sleep scale: a new instrument for assessing sleep and nocturnal disability in Parkinson's disease. J Neurol Neurosurg Psychiatry 73: 629-635.

7. Högl B, Arnulf I, Comella C, Ferreira J, Iranzo A, et al. (2010) Scales to assess sleep impairment in Parkinson's disease: critique and recommendations. Mov Disord 25: 2704-2716.

8. Takahashi K (2013) [Non-motor symptoms in premotor phase of Parkinson disease]. Rinsho Shinkeigaku 53: 974-976.

9. Guo X, Song W, Chen K, Chen X, Zheng Z, et al. (2013) Disease durationrelated differences in non-motor symptoms: a study of 616 Chinese Parkinson's disease patients. J Neurol Sci 330: 32-37.

10. Dhawan V, Dhoat S, Williams AJ, Dimarco A, Pal S, et al. (2006) The range and nature of sleep dysfunction in untreated Parkinson's disease (PD). A comparative controlled clinical study using the Parkinson's disease sleep scale and selective polysomnography. J Neurol Sci 248: 158-162.

11. Gómez-Esteban JC, Tijero B, Somme J, Ciordia R, Berganzo K, et al. (2011) Impact of psychiatric symptoms and sleep disorders on the quality of life of patients with Parkinson's disease. J Neurol 258: 494-499. 